\title{
Cardiofaciocutaneous syndrome with new ectodermal manifestations
}

\author{
Peter D Turnpenny, John C S Dean, Ian A Auchterlonie, Alan W Johnston
}

\begin{abstract}
We describe a 7 year old girl whose features satisfy the diagnosis of cardiofaciocutaneous syndrome. Her ectodermal features consist of fine, sparse hair, thin, opalescent nails, finger tip pads, generalised pigmentation of the skin, but no hyperkeratosis. Skin pigmentation and finger tip pads have not been previously reported in this syndrome. Twenty-two cases of CFC have been described but there is debate as to whether it is distinct from Noonan syndrome.
\end{abstract}

The cardiofaciocutaneous (CFC) syndrome was first described as an entity by Reynolds et $a l^{1}$ in 1986 and 22 cases have now been reported. ${ }^{2-9}$ Four cases of a Noonan-like syndrome reported by Baraitser and Patton ${ }^{10}$ and four cases of craniofaciocardioskeletal syndrome described by Cantu et $a l^{11}$ may be the same condition. The features of CFC syndrome overlap those of Noonan syndrome and there is debate as to whether they are distinct entities. ${ }^{6912}$ In CFC, ectodermal abnormalities are an essential diagnostic feature with sparse, curly hair being prominent. The spectrum of ectodermal abnormalities in Noonan syndrome is different and not essential for the diagnosis.

The subject of this report has features consistent with a diagnosis of CFC but with generalised skin pigmentation and finger tip pads, both previously unreported.

\section{Case report}

A female infant weighing $3020 \mathrm{~g}$ was delivered at 37 weeks' gestation by forceps because of fetal distress following a pregnancy complicated by maternal hypertension. Apgar scores were good but she fed poorly, vomited, and was noted to be irritable by 8 hours of age. Her OFC was $36.0 \mathrm{~cm}$ and she was noted to be dysmorphic with frontal bossing, midface hypoplasia, low set ears, a high arched palate, and widely spaced nipples. She developed seizures on the first day of life and a CT scan showed a small amount of subarachnoid blood in the brain stem region. At one year a repeat CT scan showed some ventricular dilatation but no evidence of raised intracranial pressure. A cardiac murmur was found by ultrasound to result from mild pulmonary stenosis. Her chromosome pattern and a urinary mucopolysaccharidosis screen were normal. Her OFC continued to follow the 90th centile and her height the 3 rd centile. Her bone age was delayed by 18 months at 5 years.
At 7 years she had mild developmental delay, attended normal school but one year behind for her age, required speech therapy, and received occupational therapy for mild hypotonia. She no longer had convulsions and anticonvulsants were stopped. When examined at the age of $7 \frac{1}{4}$ years she had short stature, macrocephaly with a high forehead and occipital bossing, epicanthic folds, downward slanting eyes, and short palpebral fissures (figs 1 and 2). She had low set, posteriorly rotated ears, joint laxity, pectus excavatum, fine sparse hair, prominent finger tip pads (fig 3), thin opalescent nails and generalised skin hyperpigmentation, but no hyperkeratosis. The parents said her skin was usually dry during the winter months. Investigations for hyperpigmentation showed no abnormality of serum electrolytes, liver function tests, cortisol, or ferritin.

Neither parent had clinical or dysmorphological features of CFC or Noonan syndrome but both had macrocephaly with their OFCs $>97$ th centile. Both reported normal hair growth and no learning difficulties as children.

\section{Discussion}

There is debate as to whether Noonan syndrome and CFC are different entities or represent variable expression of the same condition. It is noteworthy that this patient attended general paediatric, paediatric cardiology, dermatology, and otolaryngology clinics, as well as an earlier genetic clinic aged 3 years, without a diagnosis being made. Her findings are consistent with CFC, more than any other entity, on the basis of her marked ectodermal

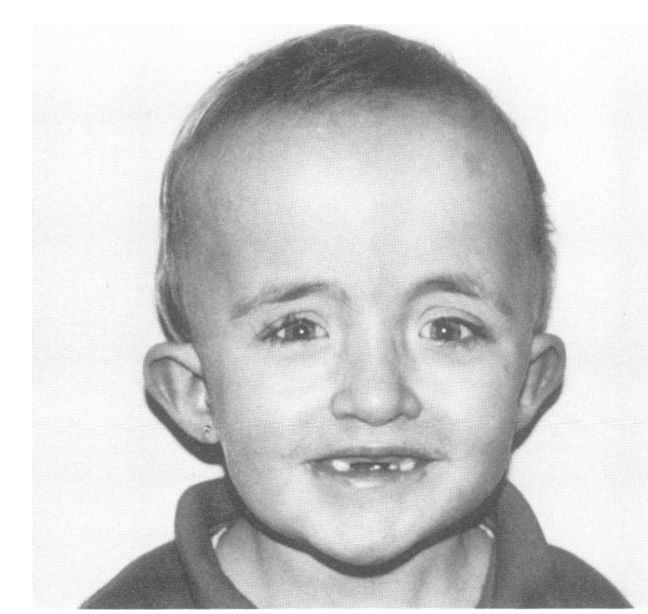

Figure 1 Craniofacial features of the subject of this report, front view. 


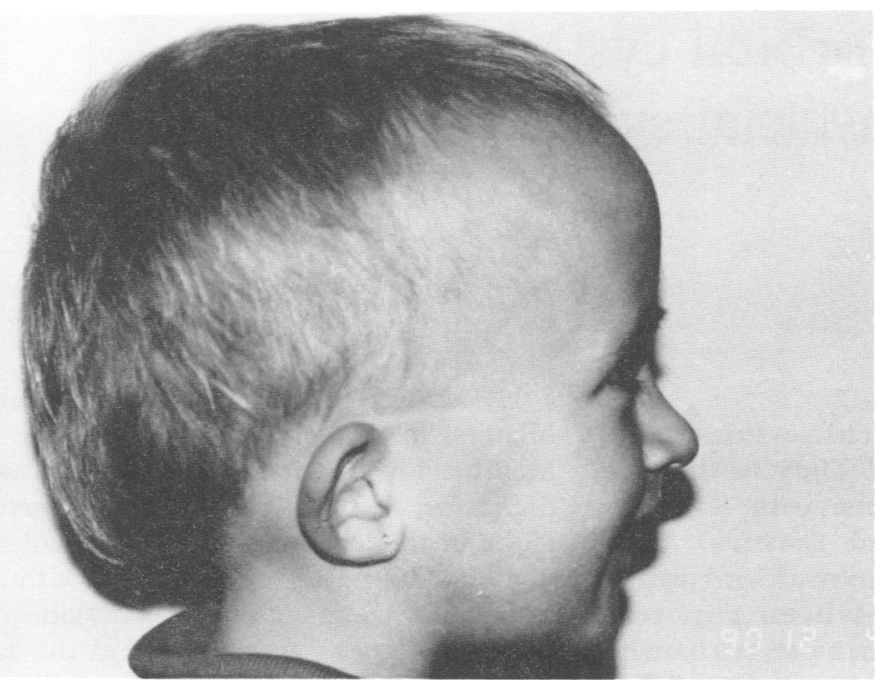

Figure 2 Craniofacial features of the subject of this report, lateral view.

features, growth delay, pulmonary stenosis, and educational difficulties. Ectodermal manifestations are the hallmark of CFC, with hypotrichosis or curly hair or both in all cases, scanty eyebrows in $36 \%(8 / 22)$, and follicular hyperkeratosis in $86 \%(19 / 22)$. Alopecia, dysplastic teeth and nails, and capillary haemangiomata are occasionally present. Ectodermal abnormalities are reported in Noonan syndrome $e^{13}$ and are said to occur in $27 \%$ of cases, consisting mainly of hyperelastic skin, lymphoedema, naevi, café au lait spots, dystrophic nails, and curly hair. Congenital heart defects are variously reported to occur in $50 \%$ and two-thirds of Noonan syndrome subjects and $68 \%(15 / 22)$ of CFC cases. Pulmonary valve stenosis $(50 \%)$ predominates over atrial septal defect $(10 \%)$ in Noonan syndrome whereas these anomalies are of equal incidence in CFC, $47 \%(7 / 15)$ and $40 \%(6 / 15)$ respectively. Mental retardation, though sometimes

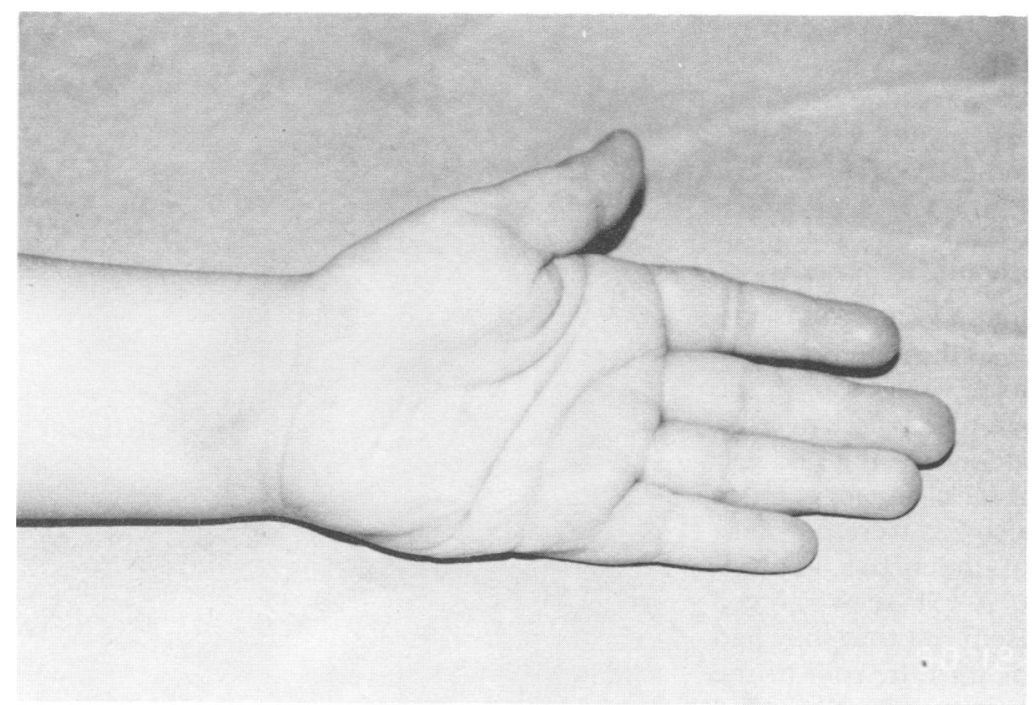

Figure 3 View of the hands showing finger tip pads. mild, is invariable in CFC but present in Noonan syndrome in up to $35 \%$ of cases. ${ }^{13}$ CFC and Noonan syndrome were both originally considered to be sporadic but autosomal dominant inheritance in Noonan syndrome is now well established. Two recent reports suggest parent to child transmission of CFC also (father-daughter ${ }^{6}$ and mother-son ${ }^{7}$ ), consistent with autosomal dominant inheritance, although $\mathrm{X}$ linkage cannot be excluded.

In our case both parents had relative macrocephaly for height but not as marked as the proband. It is not known to what extent the perinatal problems contributed both to this and to the learning difficulties, but clearly the dysmorphic features were not acquired. Relative macrocephaly is a significant, though not invariable, feature of CFC, present in $59 \%$ (13/22).

Our case did not have obvious follicular hyperkeratosis but the skin was described as 'dry' during the winter months by the parents. Dysplastic nails have previously been reported in three cases, ${ }^{148}$ but generalised skin pigmentation and finger tip pads appear to be unique in our case. The range of ectodermal anomalies within CFC is therefore widened by this report and provides some clinical evidence in favour of separate syndrome status. The relationship between CFC and Noonan syndrome may be similar to that between Noonan syndrome and neurofibromatosis type 1, where two distinct entities have an overlapping phenotype in a proportion of cases. Whether this clinical ambiguity is the result of allelic or locus heterogeneity, or perhaps of the modifying influences of other genetic or non-genetic factors, may only be clarified by DNA linkage studies or a more detailed knowledge of the molecular pathology.

1 Reynolds JF, Neri G, Herrmann JP, et al. New multiple congenital anomalies/mental retardation syndrome with cardio-facio-cutaneous involvement - the CFC syndrome. Am f Med Genet 1986;25:413-27.

2 Neri G, Sabatino G, Bertini E, Genuardi M. The CFC syndrome - report of the first two cases outside the United States. Am $\mathcal{Y}$ Med Genet 1987;27:767-71.

3 Chrzanowska K, Fryns JP, Van den Berghe H. Cardiofacio-cutaneous syndrome: report of a new patient. $A m \mathcal{F}$ Med Genet 1989;33:471-3.

4 Mucklow ES. A case of cardio-facio-cutaneous syndrome. Am $\mathcal{F}$ Med Genet 1989;33:474-5.

5 Sorge G, Di Forti F, Scarano G, Ventruto V, Zelante L, Dallapiccola B. CFC syndrome: report on three additional cases. Am $\mathcal{F}$ Med Genet 1989;33:476-8.

6 Verloes A, Le Merrer M, Soyeur D, et al. CFC syndrome: a syndrome distinct from Noonan syndrome. Ann Genet (Paris) 1988;31:230-4.

7 Lupi M, Bruschettini T, Lerone M, Romeo G. A new case of C-F-C syndrome with autosomal dominant inheritance. David $W$ Smith Workshop on Malformations and Morphogenesis, Madrid, Spain, 23-29 May 1989. Proc Greenwood Genetic Center 1990;9:118.

8 Gross-Tsur V, Gross-Kieselstein E, Amir N. Cardio-facio cutaneous syndrome: neurological manifestations. Clin Genet 1990;38:382-6.

9 Fryer AE, Holt PJ, Hughes HE. The cardio-facio-cutaneous (CFC) syndrome and Noonan syndrome: are they the same? Am $\mathcal{F}$ Med Genet 1991;38:548-51.

10 Baraitser M, Patton MA. A Noonan-like short stature syndrome with sparse hair. $\mathcal{F}$ Med Genet 1986;23:161-4.

11 Cantu JM, Sanchez-Corona J, Hernandes A, Nazara Z, Garcia-Cruz D. Individualization of a syndrome with Garcia-Cruz D. Individualization of a syndrome with
mental deficiency, macrocranium, peculiar facies, and mental deficiency, macrocranium, peculiar facies, and
cardiac and skeletal anomalies. Clin Genet 1982;22:172-9.

12 Neri G, Cappa M, Reynolds JF. The nosology of the cardio-facio-cutaneous (CFC) and Noonan syndromes. David W Smith Workshop on Malformations and Morphogenesis, Madrid, Spain, 23-29 May 1989. Proc Greenwood Genetic Center 1990;9:118.

13 Allanson JE. Noonan syndrome. $\mathfrak{F}$ Med Genet 1987;24:9-13. 